Eric Hoste

Severine Doom

Jan De Waele

Louke Delrue

Luc Defreyne

Dominique Benoit

Johan Decruyenaere

\section{Epidemiology of contrast- associated acute kidney injury in ICU patients: reply to Valette and du Cheyron}

Accepted: 3 December 2011

Published online: 25 January 2012

(C) Copyright jointly held by Springer and ESICM 2012

This reply refers to the comment available at: doi:10.1007/s00134-012-2470-y.

Dear Editor,

We thank Dr. Valette and Dr. du Cheyron [1] for their thoughtful comments on our recently published article [2]. We appreciate that they support our hypothesis that acute setting is likely caused by multiple factors. Many indications or clinical scenarios for performing a contrastenhanced computed tomography (CT) scan or angiography, such as septic or hemorrhagic shock, may also a contribute to the development of AKI. Therefore, for this specific cohort of intensive care unit (ICU) patients, we chose to use the term contrast-associated AKI (CA-AKI), rather than the generally accepted term contrastinduced AKI. kidney injury (AKI) in this specific
Dr. Valette and Dr. du Cheyron stated that some of our patients probably already had AKI before the administration of contrast agent. This view is supported by the increase in serum creatinine levels between ICU admission and the administration of contrast agent in CA-AKI patients. Following their suggestion, we analyzed the evolution of serum creatinine between the day preceding contrast administration and the day of contrast administration and found that the serum creatinine level actually decreased in patients who developed CA-AKI just before contrast exposure (Table 1). In other words, we did not observe the "natural evolution of ongoing AKI", and contrast exposure most probably played a major role in the pathophysiology of AKI in these patients.

Finally, Dr. Valette and Dr. du Cheyron suggested a comparison to a control group of patients who had not been not exposed to contrast agent. For a control group to provide meaningful information, it should have the same characteristics as the intervention group. However, the addition of the suggested control group of patients, namely, those who had undergone a CT scan without contrast agent, would introduce a major bias into the study as there would be a clinical reason why these patients were not administered contrast agent. The two most likely of these would be these patients already had AKI and, therefore, contrast was not administered, or the patients were less severely ill and there was no need to administer the contrast agent. In other words, the control patients would have completely different baseline characteristics. Also, the addition of a control group would exclude $16 \%$ of the included patients who underwent an angiography. Finally, there are many roads that will lead to AKI in ICU patients. A certain number of patients in a control group will develop AKI secondary to other reasons. Up to twothirds of ICU patients actually do develop AKI in the ICU $[3,4]$, and the majority of these patients did so without previous contrast exposure. In other words, the addition of a control group would dilute the signal and lead to false negative results.

\section{References}

1. Valette X, du Cheyron D (2012) Contrast-"induced" versus-"associated" acute kidney injury: take care with the definition. Intensive Care Med. doi: 10.1007/s00134-012-2470-y

2. Hoste EA, Doom S, De Waele J, Delrue LJ, Defreyne L, Benoit DD,

Decruyenaere J (2011) Epidemiology of contrast-associated acute kidney injury in ICU patients: a retrospective cohort analysis. Intensive Care Med 37:1921-1931. doi:

10.1007/s00134-011-2389-8

3. Hoste EA, Clermont G, Kersten A, Venkataraman R, Angus DC, De Bacquer D, Kellum JA (2006) RIFLE criteria for acute kidney injury are associated with hospital mortality in critically ill patients: a cohort analysis. Crit Care 10:R73

4. Joannidis M, Metnitz B, Bauer P, Schusterschitz N, Moreno R, Druml W, Metnitz PG (2009) Acute kidney injury in critically ill patients classified by AKIN versus RIFLE using the SAPS 3 database. Intensive Care Med 35:1692-1702

Table 1 Evolution of serum creatinine in CA-AKI and non-CA-AKI patients

\begin{tabular}{lllr}
\hline Scr $(\mathrm{mg} / \mathrm{dL})$ & $\begin{array}{l}\text { Day before contrast } \\
\text { exposure }\end{array}$ & $\begin{array}{l}\text { Day of contrast } \\
\text { exposure }\end{array}$ & $P^{\mathrm{a}}$ \\
\hline No CA-AKI & $0.83(0.58-1.25)$ & $0.77(0.55-1.09)$ & 0.165 \\
CA-AKI & $1.12(0.63-1.63)$ & $1.10(0.58-1.73)$ & 0.001 \\
\hline
\end{tabular}

Scr Serum creatinine, $C A-A K I$ contrast-associated acute kidney injury

Values are presented as the mean, with the range given in parenthesis

${ }^{a}$ Wilcoxon signed rank test for related samples
E. Hoste $(\bowtie) \cdot$ S. Doom - J. De Waele L. Delrue - L. Defreyne - D. Benoit . J. Decruyenaere Ghent University Hospital-Intensive Care Medicine, De Pintelaan 185, 9000 Ghent, Belgium e-mail: eric.hoste@ugent.be

Tel.: +32-9-3324197

Fax: +32-9-3324995 